D.N. Lucas FRCA, Angus Kennedy MD MRCP, Daryl P. Dob FRCA

\section{Dural puncture and iatrogenic pneumo- cephalus with subsequent transverse myelitis in a parturient}

Purpose: To report a case of transverse myelitis following inadvertent dural puncture and iatrogenic pneumocephalus and any possible causal relationship is explored.

Clinical features: A 32-yr-old primigravida developed a severe headache associated with pneumocephalus following accidental dural puncture when the loss of resistance to air technique was used to locate the epidural space. She was treated with oxygen 100\% to promote resorption of the air and the headache resolved. One month later she developed a sensory disturbance in her feet. Neurological examination revealed reduced sensation to cold and pain to ankle level and bilateral suppressed knee and ankle reflexes but was otherwise normal. A spinal cord lesion (epidural abscess/hematoma) was excluded with an emergency $T_{1}$ and $T_{2}$ weighted magnetic resonance imaging (MRI) scan of the lumbar spine. Over the next $48 \mathrm{hr}$ the sensory disturbance worsened to involve her legs and waist. Examination revealed a sensory loss to waist level, reduced joint position sense and vibration sense in her lower limbs and absent knee and ankle reflexes bilaterally, but normal power in both her legs. A further full length $T_{2}$ weighted MRI scan of the spine showed a small area of high signal at the level of $T_{3}$ compatible with transverse myelitis. This was treated with high dose corticosteroids and her symptoms resolved over the next three months.

Conclusion: The etiology of transverse myelitis after dural puncture in a parturient could not be identified nor could any causal link be established between the dural puncture, pneumocephalus, and subsequent transverse myelitis.

Objectif : Rapporter un cas de myélite transverse consécutive à une ponction involontaire de la dure-mère et à une pneumo-encéphalie, et explorer toute relation causale possible.

Éléments cliniques : Une primigeste de 32 ans a souffert de céphalées intenses associées à une pneumoencéphalie causée par l'effraction accidentelle de la dure-mère lors de l'utilisation de la technique de perte de résistance pour localiser l'espace épidural. Le traitement avec de l'oxygène à $100 \%$ a favorisé la résorption de l'air et éliminé les céphalées. Un mois plus tard, la patiente a ressenti des troubles sensitifs à un pied. L'examen neurologique a révélé une perte de sensation au froid et à la douleur au niveau de la cheville ainsi que la suppression bilatérale des réflexes achilléen et rotulien. Une lésion de la moelle épinière (abcès épidural/hématome) a été exclue à la suite d'un examen pondéré en $T_{1}$ et $T_{2}$ de la colonne lombaire, en imagerie par résonance magnétique (IRM) réalisé d'urgence. Pendant les $48 \mathrm{~h}$ qui ont suivi, le déficit sensitif s'est aggravé et a touché les jambes et la taille. On notait une perte sensorielle jusqu'à la taille, une diminution du sens arthrocinétique et de la pallesthésie aux membres inférieurs de même que l'absence bilatérale des réflexes achilléen et rotulien, mais une force normale aux deux jambes. Un examen supplémentaire d'IRM de la colonne, pondéré selon le paramètre tissulaire $T_{2}$ complet, a montré une petite zone de signal important au niveau de $T_{3}$, ce qui est compatible avec une myélite transverse. Le traitement avec de fortes doses de corticoïdes a éliminé les symptômes au cours des trois mois suivants.

Conclusion : On n'a pu identifier la cause d'une myélite transverse survenue après une ponction de la duremère chez une parturiente, ni un quelconque lien causal entre la ponction de la dure-mère, la pneumoencéphalie et la myélite transverse subséquente.

From the Magill Department of Anaesthesia, Intensive Care \& Pain Management and the Department of Neurology, ${ }^{*}$ Chelsea \& Westminster Hospital, 369 Fulham Road, London SW10 9NH, UK.

Address correspondence to: Dr. D.N. Lucas. Fax: 44-0208-746-8861; E-mail: lucasnel@dircon.co.uk

Accepted for publication August 9, 2000. 
$\mathrm{R}$ EGIONAL anesthesia is often blamed when postpartum neurological problems occur, particularly if there has been a complication with the regional technique itself. However such neurological problems are more often due to the processes of labour and delivery and thorough clinical examination and investigation will generally exonerate regional anesthesia.

We report the occurrence of an unusual neurological problem, transverse myelitis, one month after inadvertent dural puncture and iatrogenic pneumocephalus the possibility of a causal relationship is discussed.

\section{Case report}

A 32-yr-old primigravida presented to the delivery suite in established labour and requested epidural analgesia. She had suffered mild pregnancy induced hypertension for which no treatment had been required: otherwise there was no other past medical history of note. Prior to the epidural being sited, the diastolic blood pressure was $100 \mathrm{mmHg}$, the platelet count was $254 \times 10^{9} \cdot 1^{-1}$ and urinalysis was negative for protein.

Epidural analgesia was performed with the patient in the sitting position, at $\mathrm{L}_{3-4}$ interspace, using a $16 \mathrm{G}$ Tuohy needle with a loss of resistance to air technique. The epidural space was located at the first attempt, but coinciding with the loss of resistance to air the patient complained of a frontal headache. This partially resolved and in the absence of other neurological symptoms the anesthesiologist proceeded to pass the epidural catheter. After removing the Tuohy needle the anesthesiologist noted fluid flowing through the catheter, but he was unable to aspirate any fluid. $\mathrm{He}$ slowly administered $10 \mathrm{ml}$ bupivacaine $0.1 \%$ with fentanyl $0.0002 \%$ (preservative free) through the epidural catheter. This produced a good sensory block for labour, without hypotension or motor block. Two further epidural top-ups of $10 \mathrm{ml}$ bupivacaine $0.1 \%$ with fentanyl $0.0002 \%$ were given over the next three hours, both producing analgesia without accompanying hypotension or motor weakness. The labour progressed uneventfully and a healthy baby was born by spontaneous vaginal delivery.

Twelve hours after delivery the patient again complained of a severe generalised frontal headache. There were no other symptoms and she was managed conservatively. After a further $12 \mathrm{hr}$ the headache had considerably worsened. It was associated with neck stiffness and episodes of profuse sweating and was only partially relieved by lying down. Neurological examination showed moderate nuchal rigidity but was otherwise normal and the patient was apyrexial. However in view of the atypical nature of the headache a cranial comput- ed tomography (CT) scan was performed, which revealed a pneumocephalus (Figure); air was visible in the basal cistern, sylvian fissure and the frontal horns of the lateral ventricle. The patient was transferred to the labour ward high dependency unit and treated with supplementary oxygen via a rebreathing mask to promote resorption of the air. She was given regular codydramol and diclofenac which partially relieved the headache. A lumbar puncture was performed to exclude bacterial meningitis. The cerebrospinal fluid (CSF) showed 158 white cells per millilitre $(50 \%$ lymphocytes, $25 \%$ polymorphs, $35 \%$ monocytes), elevated protein $\left(1.17 \mathrm{~g} \cdot \mathrm{l}^{-1}\right)$, minimally reduced glucose $\left(3.9 \mathrm{mmol} \cdot \mathrm{l}^{-1}\right.$, compared with a plasma concentration of 4.9 $\mathrm{mmol} \cdot \mathrm{l}^{-1}$ ), and no organisms. She was given empirical antimicrobial therapy.

Over the next four days the patient's symptoms improved and she was discharged home on the fifth postpartum day. Three weeks later she was well with no residual symptoms.

A week later (one month after delivery) she was referred as an emergency complaining of decreased sensation in both feet and abnormal sensation in the

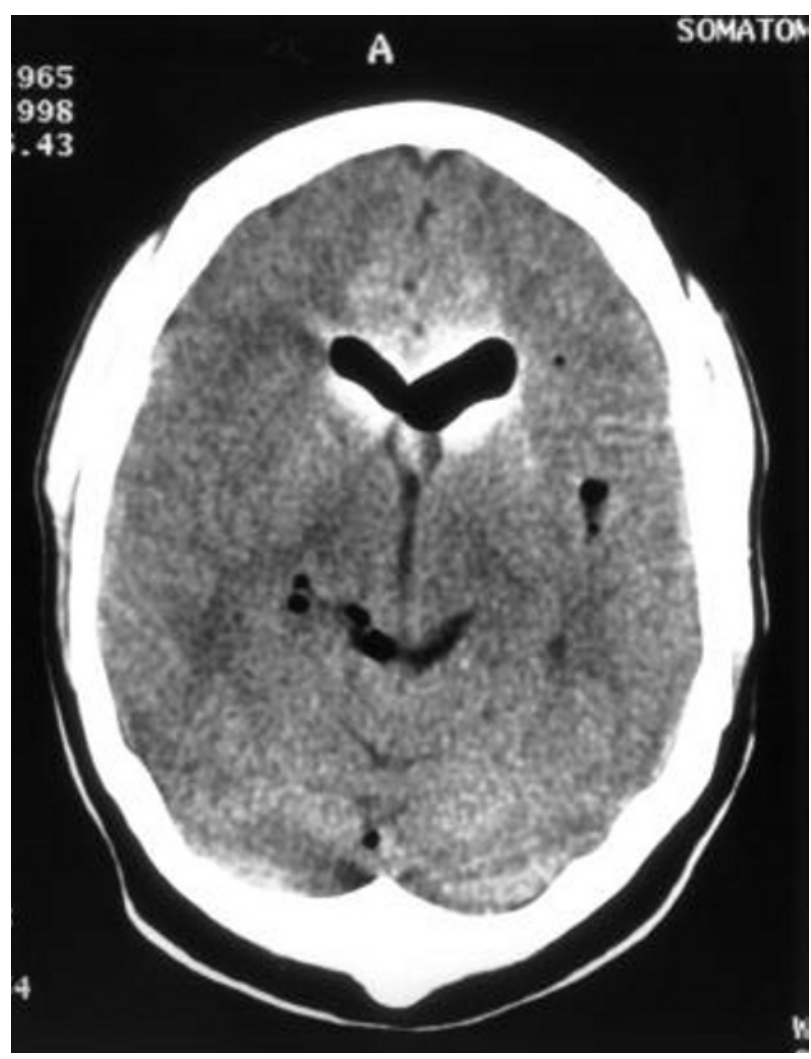

FIGURE Cranial CT scan showing air in the frontal horns of the lateral ventricles 
perineal region. She denied backache, motor weakness or sphincter disturbance. Neurological examination revealed reduced sensation to cold and pain to ankle level and bilateral suppressed knee and ankle reflexes (left worse than right) but was otherwise normal. The priority at this time was to exclude a spinal cord lesion (epidural abscess/hematoma) and an emergency $\mathrm{T}_{1}$ and $\mathrm{T}_{2}$ weighted magnetic resonance imaging (MRI) scan of the lumbar spine was performed and found to be normal. The CT scan of the patient's head was also normal. The situation became clearer over the next 48 $\mathrm{hr}$ as the sensory disturbance worsened to involve her legs and waist. She also reported a single episode of fecal incontinence and the development of circumferential pain in the $\mathrm{T}_{3-4}$ dermatone. Examination revealed a sensory loss to waist level, reduced joint position sense and vibration sense in her lower limbs and absent knee and ankle reflexes bilaterally, but normal power in both her legs. She was apyrexial. The differential diagnosis at this point included, Guillain Barré syndrome and a myelitis. A further full length $\mathrm{T}_{2}$ weighted MRI scan of the spine showed a small area of high signal at the level of $\mathrm{T}_{3}$ compatible with a diagnosis of transverse myelitis (TM). The patient was treated with high dose methylprednisolone for three days. A repeat lumbar puncture was normal. Further investigations including electromyography, autoantibody screen, CSF oligoclonal bands, viral serology and serum B12 and folate were all normal.

Over the next two months the patient's symptoms slowly resolved and three months after delivery she was well with only some slight residual numbness of her feet.

\section{Discussion}

The differential diagnosis of neurological symptoms following regional analgesia must include spinal cord compression secondary to abscess or hematoma. These were excluded in our patient. Once the diagnosis of transverse myelitis was made, the question remained of whether there could be a causal relationship between it, the iatrogenic dural puncture and pneumocephalus.

Transverse myelitis (inflammation of the spinal cord that can involve the grey and white matter) has multiple etiologies. It can present with motor and/or sensory impairment and a zone of hyperalgesia at the corresponding spinal level may be present (which was reported by our patient). Dawkins ${ }^{1}$ has described its occurrence after epidural anesthesia, where its onset was thought to be due at least in part to associated hypotension and the use of adrenaline in the epidural space (neither of these factors were present in our patient). Transverse myelitis has also been attributed to the use of spinal anesthesia ${ }^{2}$ although subsequent work attributed the myelitis to chemical contaminants rather than the spinal anesthetic itself. However its occurrence following both general anesthesia ${ }^{3}$ (the etiology in this instance believed to be a wound infection) and vaginal delivery ${ }^{4}$ highlight the pitfall inherent in attributing a causal relationship to a regional anesthetic technique.

Transverse myelitis may occur as a result of infection, demyelinating or vascular disorders, as a neurological manifestation of immune mediated disease, and as a remote effect of malignant disease. ${ }^{5}$ In our patient the recognised causes of TM were systematically excluded; viral screens were negative, spinal MRI did not reveal lesions extending over several segments and oligoclonal bands were not isolated from the CSF, autoantibody screens were normal, and serum Bl2 and folate were normal. Furthermore, TM may occur without a specific cause being identified. Tippet et al. ${ }^{6}$ reported three patients who suffered relapsing isolated acute TM. Although describing a relapsing demyelinating disease the authors suggested that this presentation of TM represents a clinical syndrome distinct from multiple sclerosis. Indeed the chance of a patient with TM progressing to develop MS is probably low; the incidence quoted in different series of patients with TM ranging from $1.6 \%$ to $8.2 \% .^{4,7}$

The role of corticosteroids in the treatment of TM is uncertain as most reports of their use are anecdotal. Available evidence suggests that they may reduce the duration and severity of attacks of TM. ${ }^{6}$

Pneumocephalus is a well recognised complication when dural puncture is associated with the loss of resistance to air technique to locate the epidural space. ${ }^{8}$ This, along with other complications, when air is used with the 'loss of resistance' technique has lead to calls for its use to be abandoned. $.^{9}, 10$ The features of pneumocephalus following dural puncture include immediate, though usually transient headache coinciding with the loss of resistance, and a subsequent atypical headache, not affected by changes in the patient's posture posture. ${ }^{8,11}$ Neurological deficit secondary to the volume effect of air in the subarachnoid space has been described ${ }^{12,13}$ but in both these cases the deficit disappeared as the air was absorbed. More serious neurological deficit (hemiparesis and hemiplegia) has been reported with pneumocephalus occurring after neurosurgery. ${ }^{14}$ These problems were also thought to be secondary to the volume effect of intracranial air and consistent with this, the neurological deficit resolved after a few days coinciding with the resorption of the intracranial air. Air injected into the epidural space may be detected for several days radi- 
ographically. It has been suggested that administration of oxygen 100\% would ameliorate the symptoms of pneumocephalus; by replacing nitrogen in the inspired gas with oxygen, the nitrogen concentration gradient is increased. This increases the speed of diffusion of nitrogen from the air collection to the surrounding tissue and then to the bloodstream. ${ }^{15}$

Before the advent of CT scanning and magnetic resonance imaging, pneumocephalography was a standard technique used for the investigation of intracranial pathology. In this technique $30-40 \mathrm{ml}$ of air were introduced into the CSF through a spinal needle after a similar volume of CSF had been removed. Side effects reported include headache, lethargy and confusion, all of which resolved without treatment. ${ }^{16} \mathrm{We}$ were unable to find any report of serious long term sequele after pneumocephalography.

In the absence of a readily identifiable causal link between the dural puncture, pneumocephalus and transverse myelitis, an immunological mechanism could be hypothesised. Virchow Robin spaces surround arteries and veins emerging from the cerebral cortex. ${ }^{17}$ They provide a route for cells in the subarachnoid space to gain entry to the brain parenchyma and have been implicated in the pathophysiology of viral encephalitis. A mechanism for the TM that occurred in our patient might be that the air introduced into the subarachnoid space following the dural puncture promoted trafficking into the central nervous system, via Virchow Robin spaces, of lymphocytes cross-reactive with myelin components, leading to demyelination. Although the one month interval between the pneumocephalus and the development of the TM might make this theory less likely, it is possible that the same mechanism was responsible for the generation of a new primary immune response to brain components leading to demyelination.

In conclusion we have presented a case of a patient who developed transverse myelitis shortly after a dural puncture complicated by pneumocephalus; despite detailed investigation we have been unable to establish any causal relationship between these events.

Acknowledgements

DNL was supported by the Obstetric Anaesthetists' Association Research Fellowship. The authors would like to thank Dr Simon Hawke for reading and advising on the immunological aspects of the manuscript.

\section{References}

1 Dawkins CJM. An analysis of the complications of extradural and caudal block. Anaesthesia 1969; 24: 554-63.
2 Dinsdale T. Spinal analgesia and cauda equina lesions. Anaesthesia 1947; 2: 17-27.

3 Gutowski NJ, Davies AO Transverse myelitis following general anaesthesia. Anaesthesia 1993; 48: 44-5.

4 Berman M, Feldman S, Alter M, Zilber N, Kahana E. Acute transverse myelitis: incidence and etiologic considerations. Neurology 1981; 31: 966-71.

5 Lipton HL, Teasdall RD Acute transverse myelopathy in adults. A follow-up study. Arch Neurol 1973; 28: 252-7.

6 Tippett DS, Fishman PS, Panitch HS. Relapsing transverse myelitis. Neurology 1991; 41: 703-6.

7 Ropper AH, Poskanzer DC The prognosis of acute and subacute transverse myelopathy based on early signs and symptoms. Ann Neurol 1978; 4: 51-9.

8 Ash KM, Cannon JE, Biehl DR Pneumocephalus following attempted epidural anaesthesia. Can J Anaesth 1991; 38: 772-4.

9 Yentis SM. Time to abandon loss of resistance to air (Letter). Anaesthesia 1997; 52: 184.

10 Saberski LR, Kondamuri S, Osinubi OY. Identification of the epidural space: is loss of resistance to air a safe technique? (Letter) Reg Anesth 1997; 22: 3-15.

11 Ablering JR, Brodsky JB. Headache immediately follow ing attempted epidural analgesia in obstetrics (Letter). Anesthesiology 1980; 52: 100-1.

12 Nay PG, Milaszkiewicz R, Jothilingam S. Extradural air as a cause of paraplegia following lumbar analgesia. Anaesthesia 1993; 48: 402-4.

13 Kennedy TM, Ullman DA, Harte FA, Saberski LR, Greenhouse BB. Limbar root compression secondary to epidural air. Anesth Analg 1988; 67: 1184-6.

14 Standefer $M$, Bay JW, Trusso $R$. The sitting position in neurosurgery: a retrospective analysis of 488 cases. Neurosurgery 1984; 14: 649-58.

15 Dexter F, Reasoner DK. Theoretical assessment of normobaric oxygen therapy to treat pneumocephalus. Anesthesiology 1996; 84: 442-7.

16 Katz $\Upsilon$, Markovits R, Rosenberg B. Pneumocephalus after inadvertent intrathecal air injection during epidural block. Anesthesiology 1990; 73: 1277-9.

17 Esiri MM, Gay D. Immunological and neuropathological significanec of the Virchow- Robin space. J Neurol Sci 1990; 100: 3-8. 